\title{
Occurrence of coronary ostial stenosis in a necropsy series of myocardial infarction, sudden death, and violent death
}

\author{
Viljo Rissanen ${ }^{1}$ \\ From the Department of Forensic Medicine, University of Helsinki, Finland
}

A postmortem coronary angiography technique employing aortic injection of contrast medium and double contrast visualization of the aortic bulb and large epicardial coronary trunks was applied to the study of coronary ostia in a series of 124 deaths from acute myocardial infarction and a series of 89 sudden deaths without recent infarction and 42 violent deaths. A stenosis of 50 per cent or more of the lumen was found in the right ostium in 45 per cent and in the left ostium in 8 per cent of infarct cases. The corresponding figures in sudden deaths were 37 per cent on the right and 4.5 per cent on the left side, and in violent deaths 7 per cent in the right ostium and none in the left. Most ostial stenoses were caused by coronary atherosclerosis. In 9 patients, two with a recent infarct and 7 sudden deaths, an ostial stenosis was the only stenosed site in the coronary arterial tree. Of these 9 patients, 7 were known to have suffered from symptomatic heart disease during life, chest pain on effort and arrhythmias being the most common complaint.

There are few documented data concerning the occurrence and significance of coronary ostial changes in patients with ischaemic heart disease. The reason for this has certainly been the difficulty which is associated with the reliable demonstration of the status of coronary ostia. The funnel-shaped coronary orifice in the aortic wall may be visualized in the clinical cine-coronary arteriogram if the semiselective injection technique of the contrast medium is applied and the radiographs are taken in suitable projections (Paulin, 1964). Even then, the contrast medium itself may conceal possible pathological changes. The selective catheterization of each coronary ostium is used nowadays in most centres for clinical angiographic study of the coronary arteries (Judkins, I967; Valle, I973). The selective technique does not demonstrate changes in the ostia.

At necropsy the estimation of stenosis in coronary orifices may be difficult with the naked eye. In most postmortem coronary angiographic techniques a cannula or a needle is inserted into the main coronary arteries for the injection of contrast medium

Received 26 June 1974

${ }^{1}$ Present address: Second Department of Medicine, University Central Hospital, $\infty 290$ Helsinki 29, Finland. Supported by grants from the Paavo Ilmari Ahvenainen Foundation and the National Research Council for Medical Sciences in Finland.
(Schlesinger, I938; Schwartz and Mitchell, I962; Fulton, 1965; Schoenmackers, 1965; Evans, 1967). The drawback of such a technique is that the aortic ostium of the coronary artery is not visualized in the radiograph. Attempts have been made in necropsy studies to assess the possible stenosis of the ostium using graduated probes (Schwartz and Mitchell, 1962; Fulton, 1965).

A postmortem coronary angiography technique employing aortic injection of contrast medium and double contrast visualization of large epicardial coronary trunks (Rissanen, 1970) was applied in the present study for the examination of aortic coronary ostia in a series of deaths from acute myocardial infarction, a series of sudden deaths without recent infarction, and a control series of violent deaths.

\section{Material and methods}

The present study formed part of a series of pathoanatomical examinations in a community-wide study of the Ischaemic Heart Disease Register, which was carried out in Helsinki in 1970 (Romo, 1973; Rissanen et al. In the press). The changes in the coronary ostia were investigated in a series of 255 medico-legal necropsies from the Department of Forensic Medicine, University of Helsinki. The subjects were subdivided into three groups: I) I24 deaths from recent myocardial infarction, 2) 89 cases of sudden death without recent 
infarction, and 3) 42 cases of violent death. The subjects in the first two groups had died suddenly without evidence of external violence. The necropsy showed no recent patho-anatomical changes in organs other than the heart which could explain the death. The hearts were examined in these cases following the principles presented by the W.H.O. Scientific Group on the Pathological Diagnosis of Acute Ischaemic Heart Disease (1970). The classification of the above-mentioned 213 cases into groups I and 2 was made on the basis of the examination of the myocardium.

At necropsy the hearts were cut transversely into slices from the apex to the base according to the instructions given by the W.H.O. Scientific Group on the Pathological Diagnosis of Acute Ischaemic Heart Disease (1970). The slices were stained with Nitro-BT for the demonstration of the infarcted areas (Nachlas and Shnitka, 1963). Blocks of myocardium were taken for histological study. The principles adopted in the W.H.O. Cooperative Study on the Pathological Diagnosis of Acute Myocardial Infarction (Bouchardy et al., 1973) were followed in the recognition of recent infarcts.

A recent myocardial infarction was demonstrated in IOI men and 23 women. The median age of men was 57 years, the age range being 30 to 83 years. In women the median age was 62 years and the age range 45 to 90 years. An old infarct scar was found in the myocardium of 63 of these 124 patients ( $51 \%)$. The heart was enlarged and hypertrophic in the majority of these cases (Table I).

The series of sudden deaths consisted of 64 men and 25 women. The median age of the former was 57 years, the age range being 35 to 78 years, and of the latter 58 years, the age range being 43 to 72 years. No recent myocardial infarction could be demonstrated in the myocardium of these subjects by the methods described above. Neither did the necropsy findings of other organs provide morphological evidence of the cause of death. The toxicological examinations also gave negative results. In 32 of these 89 subjects $(36 \%)$ an old infarct scar was found in the myocardium. Pronounced hypertrophy of the heart (heart weight more than $450 \mathrm{~g}$ ) was observed in $50(56 \%)$. The median and range values for the heart weight are given in Table 1 . Twelve of the men in the series of sudden deaths were chronic alcoholics.

The series of violent deaths consisted of 42 subjects whose death was the result of an accident, suicide, or homicide. The median age of 36 men was 47 years, the age range being 29 to 64 years. In the 6 women of the series the median age was 52 years, the age range being 43 to 64 years. No one in the series of violent deaths had an old infarct scar in the myocardium. The median values for the heart weight were smaller in the series of violent deaths than in the other two series (Table I).

Postmortem coronary angiography employing aortic injection of the contrast medium and double contrast visualization of the contour of the aortic bulb and the main coronary trunks was developed and used in the study (Rissanen, 1970). The advantage of the method was that the coronary ostia were visualized in angiograms even though the ostium was located in front of or behind the aorta (Fig. I, 4, IO, II). The angiography was performed as the first procedure in the examination of the heart. The injection of the specimens was carried out at a controlled pressure of $80 \mathrm{mmHg}(10.6 \mathrm{kPa}$ ). Thereafter the coronary arteries were opened longitudinally and examined carefully by one observer. The location of the coronary ostia in relation to the coronary sinus and aortic bulb was evaluated. The degree of stenosis in the aortic ostium and in the main trunks of the coronary arteries was visually estimated by the same observer in both the double contrast angiograms and the heart

TABLE I Median and range values for heart weight $(\mathrm{g})$ and the prevalence $(\%)$ of various degrees of stenosis in the coronary arterial tree in persons dying of recent myocardial infarction, sudden deaths without recent infarction, and violent deaths

\begin{tabular}{llll}
\hline Variable & $\begin{array}{l}\text { Myocardial } \\
\text { infarction }\end{array}$ & Sudden deaths & Violent deaths \\
\hline $\begin{array}{l}\text { Total number of cases } \\
\text { Heart weight }\end{array}$ & 124 & 89 & 42 \\
$\quad$-median & & & 415 \\
$\quad$ range & 490 & 460 & $300-540$ \\
Coronary arteries & $300-880$ & $250-880$ & \\
$\quad \begin{array}{l}\text { Complete occlusion } \\
\text { no. of cases }\end{array}$ & & & 0 \\
$\quad \%$ & 87 & 34 & 0 \\
Stenosis of 50\% or more but no occlusion & 70 & 38 & 7 \\
$\quad$ no. of cases & 33 & 42 & 17 \\
$\quad \%$ & 27 & 47 & 35 \\
No pronounced stenosis & & 13 & 83 \\
$\quad$ no. of cases & 4 & 15 & \\
\hline
\end{tabular}




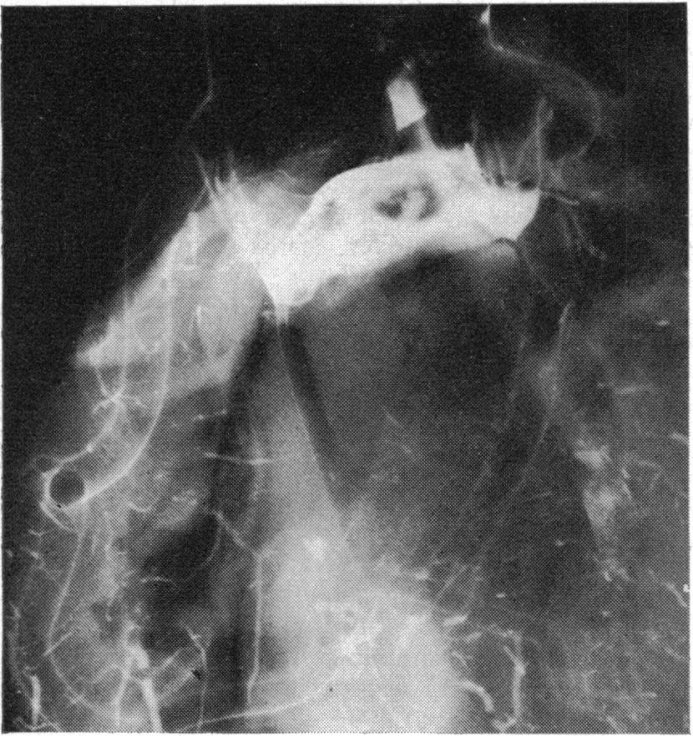

FIG. I Normal coronary ostia in a double contrast angiogram. $(X I$.

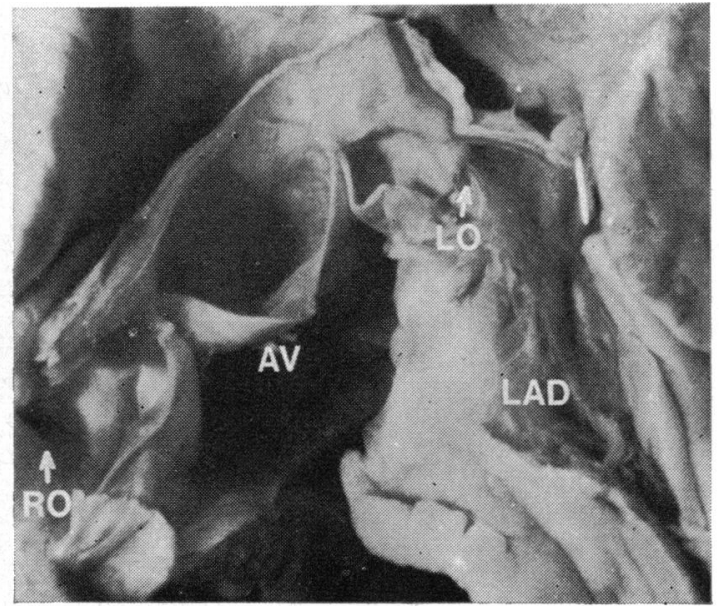

FIG. 2 Pronounced stenosis in the ostium (LO) of the longitudinally-opened left coronary artery (LAD). No atherosclerosis in the artery. Right ostium (RO) was normal. $A V=$ aortic valve.

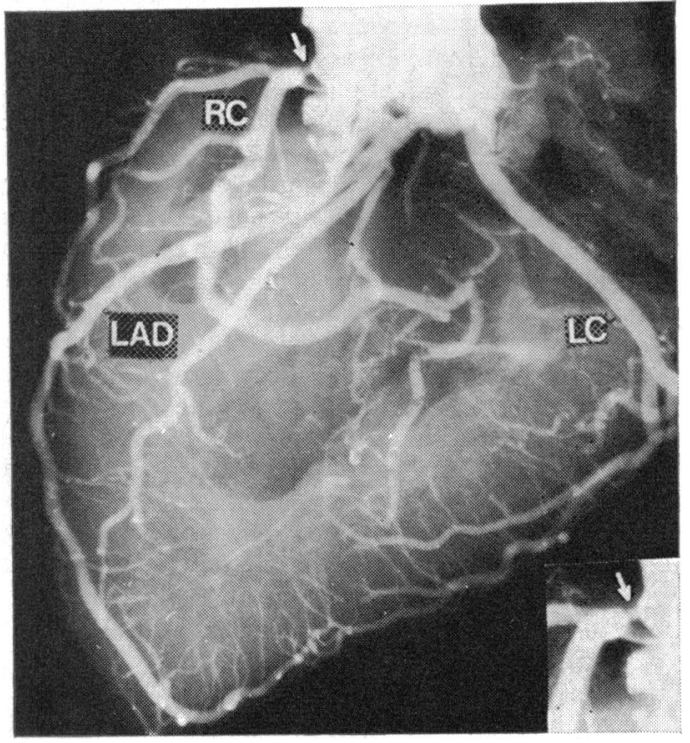

FIG. 3 Annular ostial stenosis in the right coronary artery in contrast medium angiogram. The right ostium in the natural size in the bottom right-hand corner. $R C=$ right coronary artery, $L A D=$ left anterior descending coronary artery, $L C=$ left circumflex coronary artery.

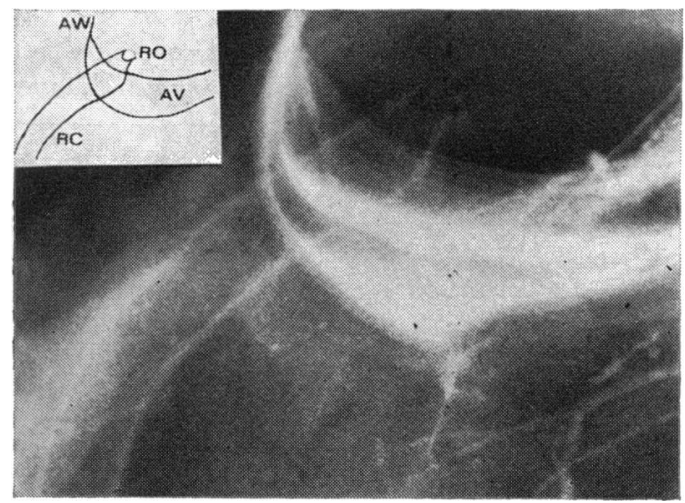

FIG. 4 An ostial stenosis of narrowing type in the right coronary ostium (RO). No stenosis more peripherally in the artery. $R C=$ right coronary artery, $A W=$ aortic wall, $A V=$ valvular cusp. $(\times 2$. 


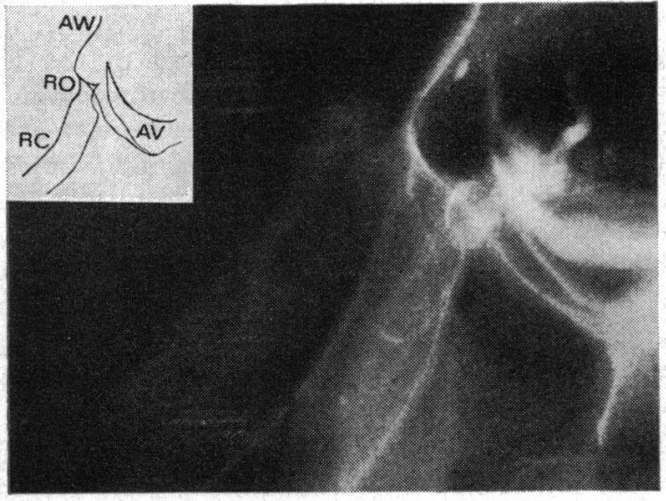

FIG. $5 A$ semiannular ostial stenosis in the right coronary ostium (RO). No stenosis more peripherally in the artery. $R C=$ right coronary artery, $A W=$ aortic wall, $A V=$ valvular cusp. ( $\times 2$.)

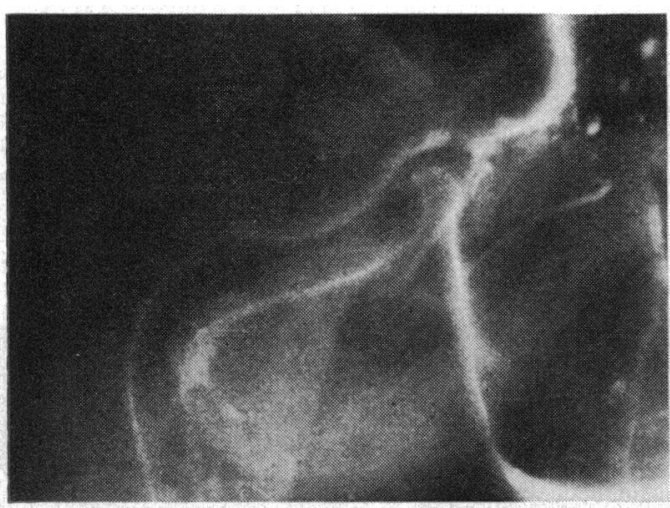

FIG. 6 A fold-like ostial stenosis in the right coronary ostium. A slightly stenosing atherosclerotic plaque on the upper wall of the artery. $(\times 2$.

specimens. Since one form of apparent ostial stenosis seen radiographically seemed to be an artefact caused by kinking in the suspended heart (Rissanen, 1970), only a stenosis that was observed in both examinations or in at least two angiographic projections was accepted. The maximal narrowing in the segment of the coronary artery extending one centimetre from the inner surface of the aorta was regarded as the measure of ostial stenosis. The ostial status was graded into four types: I) complete occlusion of the ostium, 2) a stenosis of 50 per cent or more in both the ostium and elsewhere in the coronary arteries, 3) a stenosis of 50 per cent or more in

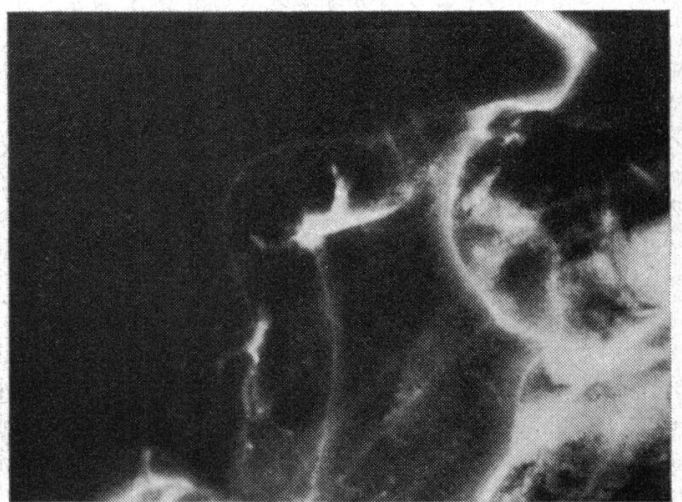

FIG. $7 A$ severe stenosis in the right coronary ostium. No stenosis more peripherally in the artery. $(\times 2$.

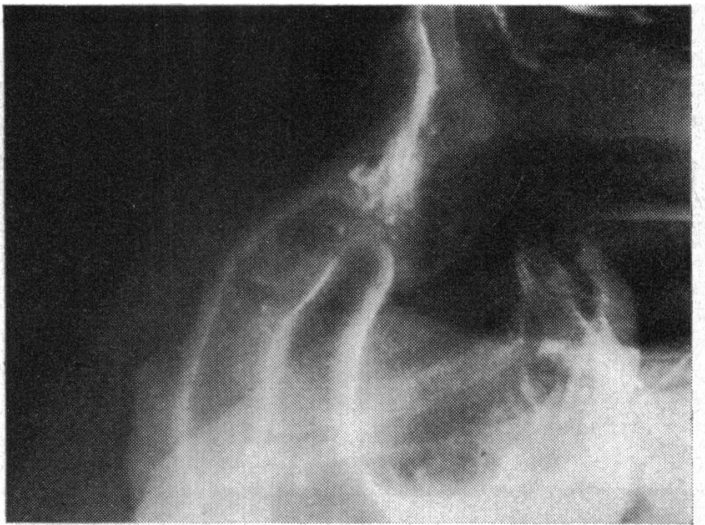

FIG. $8 A$ sclerotic stenosis of the right coronary ostium. The stenosing plaque on the roof of the ostium. $(\times 2$.

the ostium as the major obstructive lesion in the coronary arterial tree, and 4) no pronounced stenosis. In 18 cases the ostial stenosis of 50 per cent or more was found in two projections in angiography, though the lesion of the ostium had been regarded as less than half stenosing in the visual examination of the heart specimen (17\% of cases with stenosis). An ostial occlusion was observed by angiography but not by the visual examination of specimens in 8 cases ( $35 \%$ of occlusions). When the coronary arteries had been examined the procedures previously described were employed for the demonstration of acute myocardial infarction. 


\section{Results}

Coronary arteries originated in all cases from either the right or left coronary sinus. The displacement of the coronary ostia close to one or the other commissure of the sinus was uncommon. The displacement of the coronary orifice in the cranial direction above the sinus ridge was found in 9 of 213 persons $(4.2 \%)$ who died of a recent myocardial infarction or suddenly without infarction and in 2 persons of the control series who died of violent causes $(4 \cdot 8 \%)$. In 10 of II persons with upwards displacement of the ostium, the coronary artery originated immediately above the sinus ridge from the ascending aorta, and in one case, a male violent death, it originated $18 \mathrm{~mm}$ above the ridge.

An occlusion in one or more of the coronary arteries was found in 70 per cent of persons who died of myocardial infarction (Table $\mathbf{I}$ ). The prevalence of an occlusion was clearly lower in sudden deaths in whom no recent infarct could be demonstrated. In 15 per cent of the latter no pronounced stenosis was found in the coronary arteries either by angiography or by visual examination of the arteries. The prevalence of a coronary stenosis was significantly lower in persons who died of violent causes than in those who died of infarction or suddenly without infarction.

Stenosis in the coronary ostium was much more common on the right side than on the left (Table 2). Different types of stenosis are illustrated in Fig. 2-

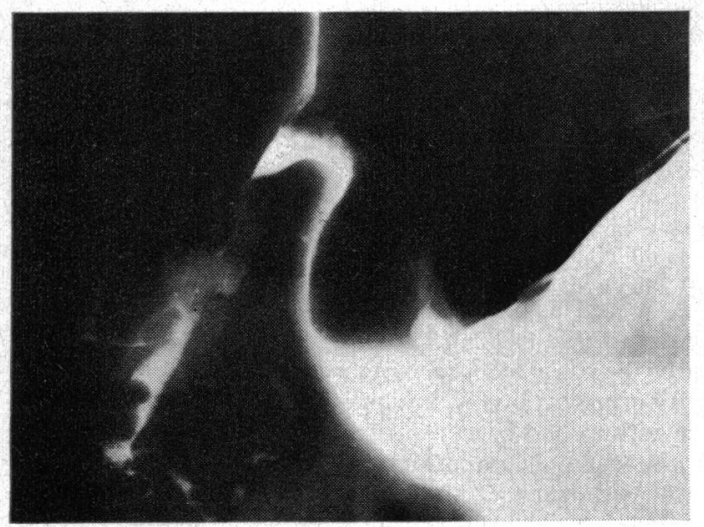

FIG. 9 An occlusion in the right coronary ostium. Calcification in the artery. Flow of the contrast medium via collaterals distal to the occlusion. $(\times 2$.
14. In patients with a recent infarction an ostial stenosis of 50 per cent or more was found in the right in 56 of 124 cases $(45 \%)$ and in the left ostium in 10 cases $(8 \%)$ ). In sudden deaths without a recent infarction the respective figures were 33 of 89 subjects $(37 \%)$ on the right side and 4 of 89 subjects $(4.5 \%)$ on the left. In violent deaths a pronounced ostial stenosis was observed in only 3 of 42 subjects $(7 \%)$, all in the right ostium. An occlusion of the first centimetre of the right coronary artery was found in 12 per cent of infarct cases and in 9 per cent of sudden deaths. The left ostium was occluded in none.

In most cases pronounced stenosis in the coronary ostium was caused by atherosclerosis. The occluding plaques were often located on the roof of the ostium (Fig. 8, 13, 14). The atherosclerotic stenosis in the coronary orifice was in most cases associated with diffuse involvement of the coronary arteries, a pronounced stenosis also being found elsewhere in the coronary arteries (Table 2). In only one man was ostial stenosis caused by syphilitic stenosis: in this case the right ostium was almost occluded. An ostial stenosis of 50 per cent or more as a major obstructive lesion in the coronary arterial tree was found in 12 persons (Table 2). Three of these were caused by a thrombus, 2 in association with an infarction and $I$ in a person who died suddenly without infarction. The characteristics of the remaining 9 patients are given in Table 3. One man and one woman had a

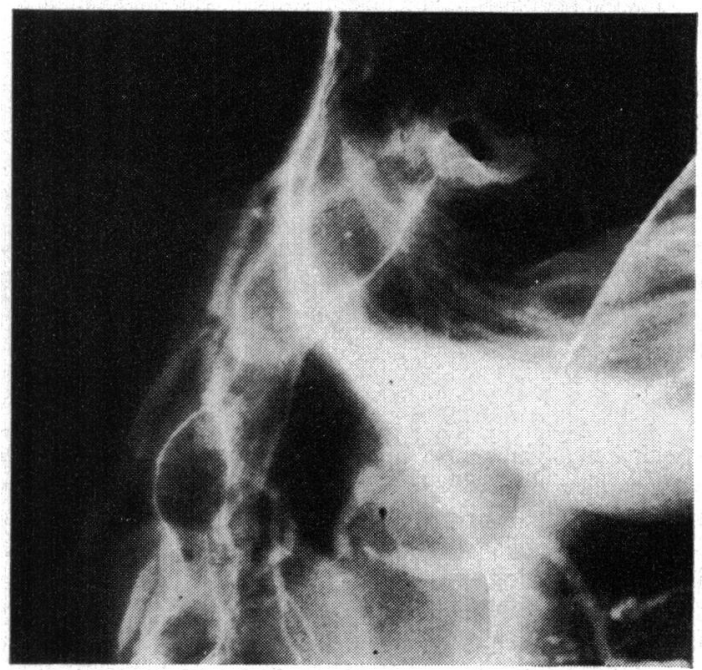

FIG. Io $A$ severely calcified ostial stenosis in the right coronary artery. $(\times 2$. 
TABLE 2 Prevalence (\%) of various types of ostial stenosis in series of deaths from recent myocardial infarction, sudden deaths without recent infarction and violent deaths

\begin{tabular}{|c|c|c|c|c|c|c|c|c|c|c|c|c|}
\hline \multirow[t]{2}{*}{ Ostial status } & \multicolumn{4}{|c|}{$\begin{array}{l}\text { Myocardial infarction } \\
\text { (I24 cases) }\end{array}$} & \multicolumn{4}{|c|}{$\begin{array}{l}\text { Sudden deaths } \\
(89 \text { cases })\end{array}$} & \multicolumn{4}{|c|}{$\begin{array}{l}\text { Violent deaths } \\
(42 \text { cases })\end{array}$} \\
\hline & \multicolumn{2}{|c|}{$\begin{array}{l}\text { Right ostium } \\
\text { No. of } \\
\text { cases \% }\end{array}$} & \multicolumn{2}{|c|}{$\begin{array}{l}\text { Left ostium } \\
\text { No. of } \\
\text { cases } \%\end{array}$} & \multicolumn{2}{|c|}{$\begin{array}{l}\text { Right ostium } \\
\text { No. of } \\
\text { cases } \%\end{array}$} & \multicolumn{2}{|c|}{$\begin{array}{l}\text { Left ostium } \\
\text { No. of } \\
\text { cases \% }\end{array}$} & \multicolumn{2}{|c|}{$\begin{array}{l}\text { Right ostium } \\
\text { No. of } \\
\text { cases \% }\end{array}$} & \multicolumn{2}{|c|}{$\begin{array}{l}\text { Left ostium } \\
\text { No. of } \\
\text { cases \% }\end{array}$} \\
\hline Complete occlusion & 15 & 12 & ० & $\circ$ & 8 & 9 & $\circ$ & $\circ$ & ० & $\circ$ & ० & 0 \\
\hline $\begin{array}{l}50 \% \text { stenosis in ostium and } \\
\text { elsewhere in coronary } \\
\text { arteries }\end{array}$ & 37 & 30 & 10 & 8 & I8 & 20 & 3 & 3 & 3 & 7 & 0 & 0 \\
\hline $\begin{array}{l}50 \% \text { stenosis in ostium as } \\
\text { major obstructive lesion } \\
\text { in coronary arterial tree }\end{array}$ & 4 & 4 & $\circ$ & $\circ$ & 7 & 8 & I & I & $\circ$ & $\circ$ & $\circ$ & 0 \\
\hline No pronounced stenosis & 68 & 54 & II 4 & 92 & 56 & 63 & 85 & 96 & 39 & 93 & 42 & 100 \\
\hline
\end{tabular}

recent infarct in the myocardium; 7 women had died suddenly. The ostial stenosis was annular in 2 cases, semiannular or fold-like in 5 cases, and symmetrical in 2 cases (Fig. 2-7). In one woman ostial stenosis was found in both the orifice of the hypoplastic right coronary artery and the orifice of the left circumflex coronary artery (Fig. 12). The left aortic ostium was affected in only one of these subjects (Fig. 2). Of the 9 subjects, 7 had suffered from known symptomatic heart disease, chest pain on effort and arrhythmias being the most common complaints. ST and T alterations in the electrocardiogram had been recognized in 3 subjects.

\section{Discussion}

In the majority of subjects there seems to be only a slight variation in the position of the coronary ostia. No exception was found in the present series to the rule that the right coronary artery originates from
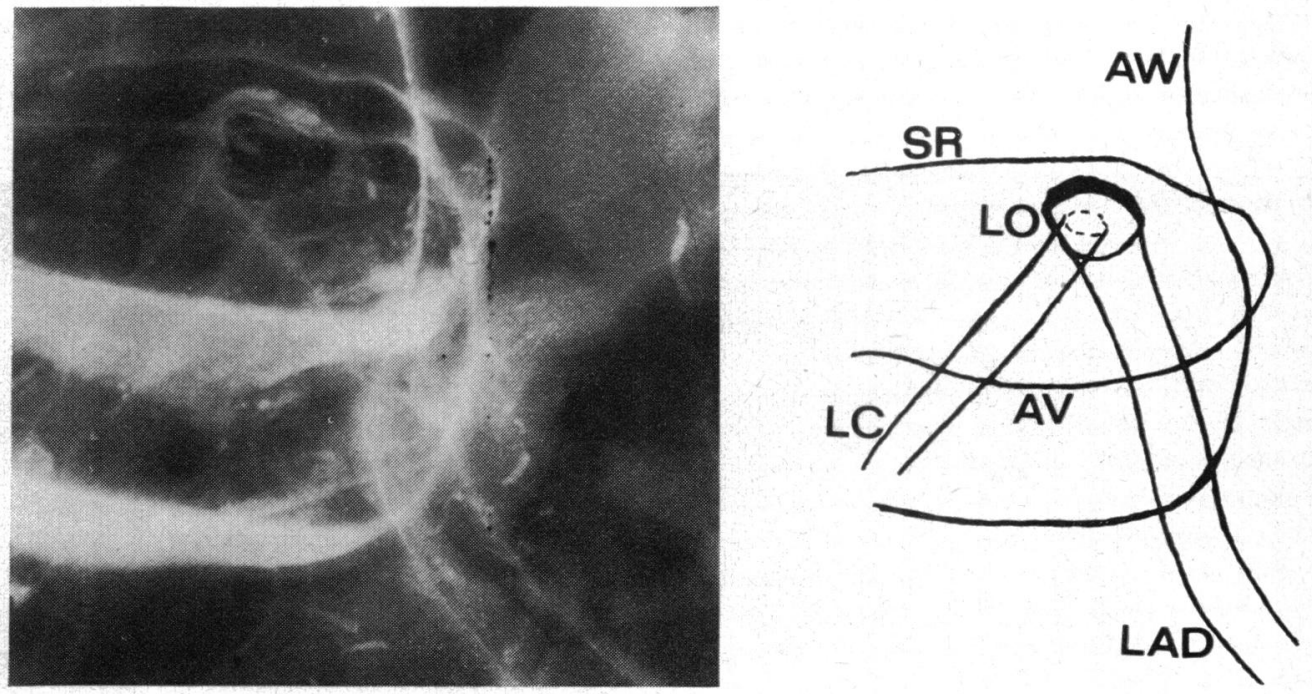

F1G. I I An ostium with calcified walls of the left coronary artery behind the aorta. $L O=$ left ostium, $L A D=$ left anterior descending coronary artery, $L C=$ left circumflex coronary artery, $A W=$ aortic wall, $A V=$ valvular cusp, $S R=$ sinus ridge. $(\times 2$. 
TABLE 3 Characteristics in 9 persons with an ostial stenosis as major obstructive lesion in coronary arteries

\begin{tabular}{|c|c|c|c|c|c|c|c|}
\hline $\begin{array}{l}\text { Case } \\
\text { No. }\end{array}$ & Sex & $\begin{array}{l}\text { Age } \\
(y r)\end{array}$ & Previous history & $\begin{array}{l}\text { Mode of } \\
\text { death }\end{array}$ & $\begin{array}{l}\text { Ostial } \\
\text { stenosis }\end{array}$ & $\begin{array}{l}\text { Heart } \\
\text { weight } \\
(g)\end{array}$ & Other pathology in the heart \\
\hline I & F & 47 & $\begin{array}{l}\text { Previous carditis; } \\
\text { chest pains and arrhythmias } \\
\text { ECG: } \mathrm{ST} \text { and } \mathrm{T} \text { changes }\end{array}$ & $\begin{array}{r}\text { Sudden } \\
\text { death }\end{array}$ & $\begin{array}{l}\text { Left, annular } \\
\quad \text { (Fig. 2) }\end{array}$ & 360 & No scar; no valvular disease \\
\hline 2 & $\mathbf{F}$ & 64 & $\begin{array}{l}\text { Previous rheumatic fever; } \\
\text { chest pains and dyspnoea } \\
\text { ECG: LVH, ST and T } \\
\text { changes }\end{array}$ & $\begin{array}{r}\text { Sudden } \\
\text { death }\end{array}$ & $\begin{array}{l}\text { Right, annular } \\
\text { (Fig. 3) }\end{array}$ & 550 & $\begin{array}{l}\text { LVH, no scar; aortic valvular } \\
\text { stenosis; endocardial } \\
\text { thickening }\end{array}$ \\
\hline 3 & $\mathrm{~F}$ & 55 & $\begin{array}{l}\text { No known heart symptoms; } \\
\text { chronic alcoholism }\end{array}$ & $\begin{array}{l}\text { Sudden } \\
\text { death }\end{array}$ & $\begin{array}{l}\text { Right, narrowing } \\
\text { (Fig. 4) }\end{array}$ & 540 & $\begin{array}{l}\text { Fibrosis in posterior } \\
\text { wall of } \mathrm{LV}\end{array}$ \\
\hline 4 & $\mathrm{~F}$ & 55 & Chest pains and dyspnoea & $\begin{array}{r}\text { Sudden } \\
\text { death }\end{array}$ & $\begin{array}{l}\text { Right, semi- } \\
\text { annular (Fig. 5) }\end{array}$ & 460 & $\begin{array}{l}\text { Fibrosis in posterior wall of } \\
\text { LV }\end{array}$ \\
\hline 5 & $\mathbf{F}$ & 64 & Arrhythmias & $\begin{array}{r}\text { Sudden } \\
\text { death }\end{array}$ & $\begin{array}{l}\text { Right, fold-like } \\
\text { (Fig. 6) }\end{array}$ & 350 & $\begin{array}{l}\text { Fibrosis in walls of left } \\
\text { ventricle }\end{array}$ \\
\hline 6 & $\mathrm{~F}$ & 52 & Chest pains and dyspnoea & $\begin{array}{r}\text { Sudden } \\
\text { death }\end{array}$ & $\begin{array}{l}\text { Right, semi- } \\
\text { annular (Fig. 7) }\end{array}$ & 420 & $\begin{array}{l}\text { Congenital muscular defect } \\
\text { in the apex; endocardial } \\
\text { fibrosis; scar in papillary } \\
\text { muscles }\end{array}$ \\
\hline 7 & $\mathrm{~F}$ & 64 & $\begin{array}{l}\text { Chest pains; ECG: ST } \\
\text { depressions }\end{array}$ & Infarct & $\begin{array}{l}\text { Right aortic, left } \\
\text { circumflex } \\
\text { coron. art } \\
\text { (Fig. 12) }\end{array}$ & 360 & $\begin{array}{l}\text { Rheumatic aortic valvular } \\
\text { stenosis, thickening of } \\
\text { mitral valve }\end{array}$ \\
\hline 8 & $\mathrm{~F}$ & 56 & $\begin{array}{l}\text { Dyspnoea before death; } \\
\text { chronic leukaemia, } \\
\text { anaemia }\end{array}$ & $\begin{array}{r}\text { Sudden } \\
\text { death }\end{array}$ & Right, narrowing & 440 & No scar; no valvular disease \\
\hline 9 & $\mathbf{M}$ & 57 & $\begin{array}{l}\text { Clinical heart disease of } \\
\text { unknown quality; } \\
\text { chronic alcoholism, } \\
\text { polyneuropathy }\end{array}$ & Infarct & $\begin{array}{l}\text { Right, semi- } \\
\text { annular }\end{array}$ & 430 & No scar; no valvular disease \\
\hline
\end{tabular}

the right coronary sinus and the left coronary artery from the left coronary sinus. Ectopic origin of one coronary artery with transposition from the sinus of Valsalva of the opposite side is a rare varia-

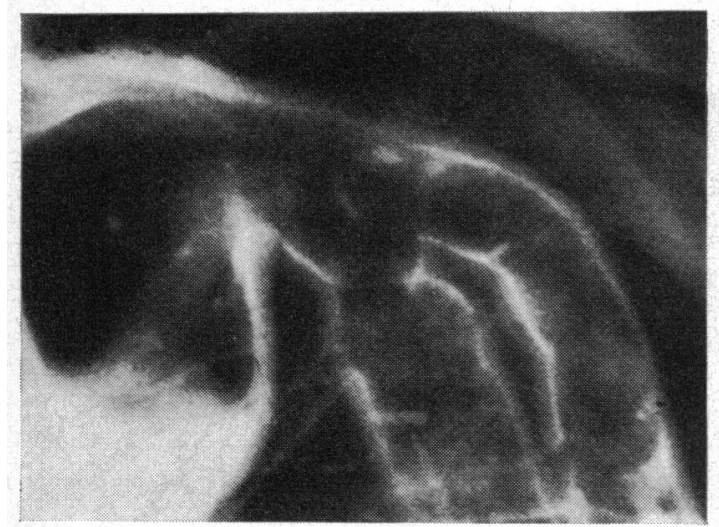

FIG. I2 $A$ narrowing in the ostium of the left circumflex coronary artery. The aortic ostium is free. $(\times 3$. tion (White and Edwards, I948; Hackensellner, 1955). Experimental flow measurements in models have suggested that if the coronary arteries are given off from the ascending aorta above the aortic bulb,

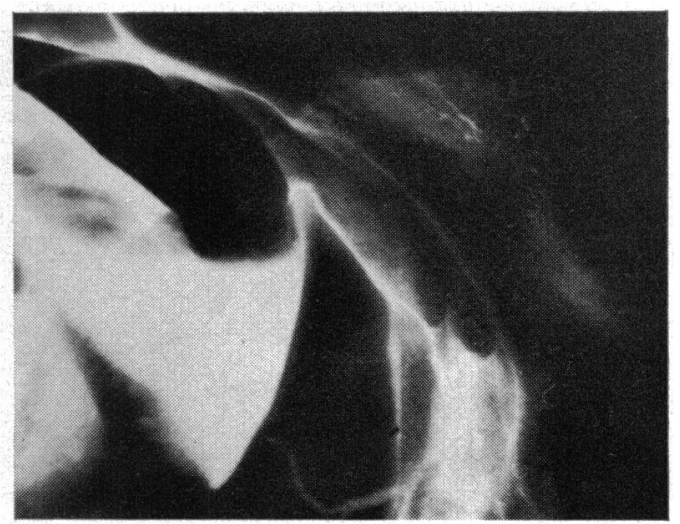

FIG. I3 A small atherosclerotic plaque on the roof of the left coronary ostium. ( $\times 2$. 


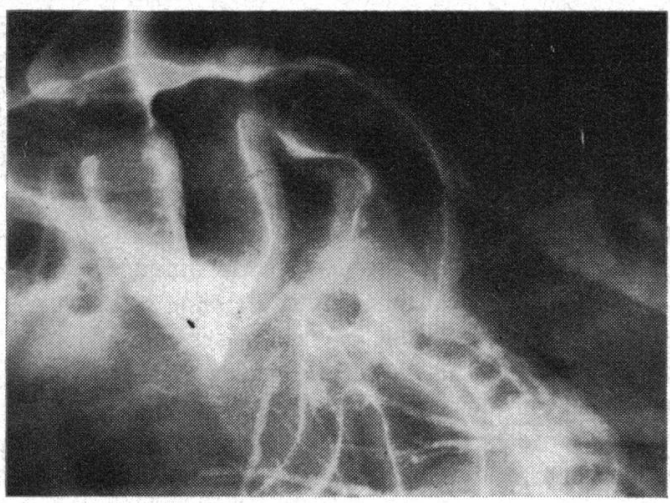

FIG. I4 $A$ sclerotic stenosis of the left coronary ostium. The stenosing plaque on the roof of the ostium. $(\times 2$.

coronary flow might be impaired owing to unfavourable mechanical turbulence and skimming of blood (Bellhouse, Bellhouse, and Reid, 1968). It is generally believed, however, that the slightly anomalous displacement of the coronary ostium from its usual position is of no consequence for the coronary circulation (Paulin, 1964). The low frequency of slightly anomalous origin of coronary ostia above the sinus ridge, which was found in the present series equally among those who had myocardial infarction and sudden death and in the series of violent deaths, seems to support the latter view. In the previous studies the frequencies of the ostia above the sinus ridge have been 5 of 1000 hearts studied post mortem by Hackensellner (1955) and 18 of 356 hearts in the postmortem series of Manninen, Rissanen, and Halonen (1970).

The prevalence of a stenosis of 50 per cent or more of the lumen in the right coronary ostium was as high as 45 per cent of the present infarct cases and 37 per cent in sudden deaths. Heggtveit (1967) has shown previously in a postmortem study of patients who died in hospital of myocardial infarction that stenosing ostial changes were present in 74 per cent of the cases. Ostial changes were also found in 52 per cent of patients without infarction. Heggtveit graded the reduction in the size of the ostium on a simple scale from $\circ$ (no stenosis) to 4 (complete obliteration). The prevalence of stenosis graded by Heggtveit from 2 to 4, which probably corresponds to the present grades of stenosis from 50 per cent to occlusion, was 39 per cent in his series of myocardial infarction (Heggtveit, 1967). The prevalence of total occlusion in the right coronary ostium, in 12 per cent of the present series of deaths from myocardial infarction, was clearly higher than that in the series of Heggtveit, who found an occlusion of the ostium in 4 of 194 infarct patients. In a recent series of living patients who were studied with clinical cine-coronary arteriography, a stenosis of 75 per cent of the lumen was demonstrated between the right coronary ostium and conus branch in 23 of 639 patients (Gensini and Kelly, 1972). The different compositions of the materials and methodological differences may explain the discrepancies in the results. It is not surprising that the stenotic changes in the right coronary ostium are most common in a series of sudden deaths from myocardial infarction, rather high in patients who have died of an infarction at hospital (Heggtveit, 1967) and less common in patients who are studied with clinical coronary arteriography for the confirmation of the diagnosis of coronary heart disease (Gensini and Kelly, 1972).

The great difference in the prevalence of ostial stenosis between the right and left coronary artery was a conspicuous feature in the present series, the right-to-left ratio being $6: 1$ in persons with a recent infarct and 8:I in sudden deaths. A similar tendency to a difference between the ostia has also been found in previous studies (Fulton, I965; Heggtveit, 1967). The explanation may lie in the gross anatomical and microanatomical difference which has been demonstrated between the right and left coronary ostium (Boucek, Takashita, and Brady, I965). Blankenhorn (1967) has shown wide differences in the physical properties of the coronary ostia and has stated that this may act as one determinant of the pattern of infarction. The differences may be caused by restriction of the coronary orifice by the surrounding aortic wall and may affect coronary blood flow. Boucek et al. (1965) demonstrated a circumferential sphincter-like muscle mass in the right coronary orifice of many patients. They suggested that this muscle might alter the dimensions of the orifice and thus offer a resistance to the pressure and flow characteristics of blood from the aorta. The different anatomical and functional properties of the ateries may, at least in part, explain the more common distribution of the atherosclerotic plaques into the ostium of the right coronary artery as compared with that of the left coronary artery.

Atherosclerotic involvement of the ostium was the most common cause of the occurrence of ostial stenosis in the present series, which is in agreement with the findings of previous postmortem studies (Fulton, 1965; Schoenmackers, 1965; Heggtveit, 1967). In the present series the atherosclerotic stenosis in the coronary orifice seemed to be associated with diffuse involvement of the coronary arteries by atherosclerosis, a pronounced stenosis also being demonstrable elsewhere in the coronary 
arteries in most cases. Schoenmackers (1965) has stated that ostial stenosis may be the only obstructive site in the coronary tree, particularly at the early phase of the atherosclerotic process. It is possible that some of the ostial stenoses were caused by early atheroma in the 9 cases in this series (Table 3) in which no stenosis was found elsewhere in the coronary arteries. Since the present study was a part of an extensive community-wide study on ischaemic heart disease, it was unfortunately not possible to carry out histological studies of the changes in the coronary ostia to determine this.

In only one man in the present series was ostial stenosis attributed to syphilitic aortitis, which is the classic aetiology (Heggtveit, 1964). In a few persons who died of ischaemic heart disease the ostial stenosis was caused by a thrombus. An interesting group was formed by those 9 persons who died suddenly and in whom the ostial stenosis was the only pronounced stenosed site in the coronary arterial tree. Heggtveit (I967) previously found ostial stenosis as the major obstructive lesion responsible for infarction in Io of 194 patients with fatal myocardial infarction. Of the present 9 patients, 7 were known to have suffered from a symptomatic heart disease. In some cases the macroscopical visual examination of specimens and the radiography (e.g. Fig. 2, 3, 4, 12) gave an impression that the ostial stenosis was non-sclerotic. A congenital arterial hypoplasia complicated by the progressive thickening of the aortic intima by advancing age may be one explanation for these cases. An inflammatory aetiology as a cause of ostial stenosis has been proposed by Schoenmackers (1965). Aschoff nodules may occur in acute rheumatic heart disease in the adventitia of the aorta near a coronary vessel (Hudson, 1965). A history of a previous carditis in one patient and necropsy findings of a rheumatic heart disease in 2 present patients may support the theory of inflammatory aetiology. It has also been demonstrated that high perfusion pressure during surgical insertion of aortic prostheses may cause injury by overdistending the vessels; subsequently a repair process may produce intimal thickening in the coronary ostia which has caused disabling angina pectoris within 3 months of operation and later death (Silver et al., 1969). None of the present patients had been an object of open-heart surgery or selective clinical coronary arteriography.

Of the present 9 patients in whom the ostial stenosis was the only stenosed site in the coronary artery tree, 8 were women. The disease history in symptomatic cases was that of ischaemic heart disease. The reports concerning angina pectoris and myocardial ischaemia or infarction in patients with normal coronary arteriograms have often included women (Neill, Kassebaum, and Judkins, 1968; Eliot, and Bratt, 1969), though the occurrence of this combination equally in both sexes has also been reported (Bemiller, Pepine, and Rogers, 1973). The most frequent explanation for these symptoms without detected coronary disease may be the incorrect interpretation of the coronary arteriograms (James, 1970). The ostial changes which have been described in the 9 patients of the present series may be particularly difficult to demonstrate with selective clinical coronary arteriography. It is possible that this type of coronary artery disease may cause an ischaemic heart disease of mild degree. In men the extensive atherosclerosis developing in the coronaries may largely mask the effect of nonsevere ostial stenosis, while in women it may more often remain as the only significant cause of ischaemia.

\section{References}

Bellhouse, B. J., Bellhouse, F. H., and Reid, K. G. (1968). Fluid mechanics of the aortic root with application to coronary flow. Nature (London), 219, 1059.

Bemiller, C. R., Pepine, C. J., and Rogers, A. K. (1973). Long-term observations in patients with angina and normal coronary arteriograms. Circulation, 47, 36.

Blankenhorn, D. H. (1967). A study of the orifice of the human coronary artery. Proceedings of the Society for Experimental Biology and Medicine, 126, 418.

Boucek, R. J., Takashita, R., and Brady, A. H. (1965). Microanatomy and intramural physical forces within the coronary arteries (man). Anatomical Record, 153, 233.

Bouchardy, B., Joliat, G., Majno, G., Lehmann, L., Mainguet, J., Rissanen, V., Vaněcek, R., Fejfar, Z., Sobin, L., and Uemura, K. (1973). The pathological diagnosis of acute myocardial infarction. Preliminary results of a WHO cooperative study. Bulletin of the World Health Organization, 48, 23.

Eliot, R. S., and Bratt, G. (1969). The paradox of myocardial ischemia and necrosis in young women with normal coronary arteriograms. Relation to abnormal hemoglobinoxygen dissociation. American fournal of Cardiology, 23, 633.

Evans, H. (1967). Postmortem angiography. A new medium and technique. Archives of Pathology, 83, 479.

Fulton, W. F. M. (1965). The Coronary Arteries. Arteriography. Microanatomy and Pathogenesis of Obliterative Coronary Artery Disease. Charles C. Thomas, Springfield, Illinois.

Gensini, G. G., and Kelly, A. E. (1972). Incidence and progression of coronary artery disease. An angiographic correlation in 1,263 patients. Archives of Internal Medicine, 129, 814 .

Hackensellner, H. A. (1955). Koronaranomalien unter 1000 auslesefrei untersuchten Herzen. Anatomischer Anzeiger, I01, 123.

Heggtveit, H. A. (1964). Syphilitic aortitis: a clinicopathologic autopsy study of 100 cases, 1950 to 1960. Circulation, 29, 346.

Heggtveit, H. A. (1967). The role of coronary ostial stenosis in the etiology of myocardial infarction. Pathologia et Microbiologica, 30, 716.

Hudson, R. E. B. (1965). Pathology of acute rheumatism. In Cardiovascular Pathology, Vol. 1, p. 931. Edward Arnold, London. 
James, T. N. (1970). Editorial. Angina without coronary disease. Circulation, 42, 189.

Judkins, M. P. (1967). Selective coronary arteriography. Part I. A percutaneous transfemoral technic. Radiology, 89, 815.

Manninen, V., Rissanen, V. T., and Halonen, P. I. (I970). Coronary ostium outside the aortic sinus. A factor in the aetiology of ischaemic heart disease. Advances in Cardiology, 4, 94.

Nachlas, M. M., and Shnitka, T. K. (1963). Macroscopic identification of early myocardial infarcts by alterations in dehydrogenase activity. American fournal of Pathology, 42, 379.

Neill, W. A., Kassebaum, D. G., and Judkins, M. P. (1968). Myocardial hypoxia as the basis for angina pectoris in a patient with normal coronary arteriograms. New England fournal of Medicine, 279, 789.

Paulin, S. (1964). Coronary angiography. A technical, anatomical and clinical study. Acta Radiologica, Suppl. 233.

Rissanen, V. T. (1970). Double contrast technique for postmortem coronary angiography. Laboratory Investigations, 23, 517.

Rissanen, V., Romo, M., Sarna, S., and Siltanen, P. Coronary deaths in persons aged 65 or younger in Helsinki in 1970: with special reference to patho-anatomic findings in hearts. Acta Medica Scandinavica In the press.

Romo, M. (1973). Factors related to sudden death in acute ischaemic heart disease. A community study in Helsinki. Acta Medica Scandinavica, Suppl. 5, p. I.
Schlesinger, M. J. (1938). An injection plus dissection study of coronary artery occlusions and anastomoses. American Heart fournal, 16, 528.

Schoenmackers, J. (1965). Die Angiomorphologie der Koronarogramme. Morphologische Grundlagen, Grenzen der Darstellung und Deutung. Fortschritte auf dem Gebiete der Röntgenstrahlen und der Nuklearmedizin, 102, 349.

Schwartz, C. J., and Mitchell, J. R. A. (1962). The relation between myocardial lesions and coronary artery disease. I An unselected necropsy study. British Heart fournal, 24, 761 .

Silver, M. D., Wigle, E. D., Trimble, A. S., and Bigelow, W. G. (1969). Iatrogenic coronary ostial stenosis. Archives of Pathology, 88, 73.

Valle, M. (1973). Postoperative coronary angiography. Acta Radiologica, Suppl. 333.

White, N. K., and Edwards, J. E. (1948). Anomalies of the coronary arteries. Archives of Pathology, 45, 766.

W.H.O. Scientific Group on the Pathological Diagnosis of Acute Ischaemic Heart Disease (1970). The Pathological Diagnosis of Acute Ischaemic Heart Disease. World Health Organization. Technical Report Series, No. 441.

Requests for reprints to Dr. V. Rissanen, Second Department of Medicine, University Central Hospital, 00290 Helsinki 29, Finland. 